\title{
Paradoks Pelayanan Kesehatan Ibu dan Anak (Studi Kasus Di Provinsi Sulawesi Tenggara)
}

\author{
Erni Qomariyah \\ Universitas Halu Oleo
}

Paradox of Maternal and Baby Healthcare Service

(A Case Study in Sulawesi Tenggara Provinsi)

\begin{abstract}
Abstrak
Tujuan penelitian ini untuk melihat bahwa kebijakan desentralisasi sektor kesehatan merupakan strategi penting dalam penyelenggaraan pelayanan kesehatan untuk masyarakat. Prinsip dasarnya adalah pelayanan publik yang paling efisien seharusnya diselenggarakan oleh otoritas yang memiliki kontrol geografis yang paling minimal. Pemerintah daerah mungkin memiliki cukup otoritas dan akses pada sumber-sumber keuangan, akan tetapi jika tidak dikelola dengan seksama, desentralisasi tidak akan menghasilkan manfaat bagi daerah. Hasil penelitian menunjukkan bahwa dalam pelayanan publik kesehatan ibu dan anak belum menggembirakan. Banyak faktor ynag menjadi penyebabnya, antara lain : 1) Sulawesi Tenggara merupakan provinsi kedua terendah di Indonesia dalam proses kelahiran yang ditolong tenaga kesehatan, 2) Semakin memburuknya ketersediaan Pos Persalinan Desa (Polindes) dimana jumlah desa yang harus dilayani oleh setiap satu Pustu menurun. Komitmen pemerintah daerah dengan menyediakan anggaran yang cukup besar di bidang kesehatan harus dimbangi dengan penyediaan fasilitas dan kemudahan pelayanan kesehatan. Karena Sulawesi Tenggara sebenarnya merupakan provinsi yang meraih PAD tertinggi di pulau Sulawesi tetapi justru kemiskinannya menduduki peringkat ke 11 secara nasional.
\end{abstract}

Kata kunci: Paradoks, Desentralisasi Kesehatan, Pelayanan Publik, Kesehatan Ibu dan Anak

\begin{abstract}
The purpose of this study to see that the policy of decentralization of the health sector is an important strategy in the administration of health services for the community. The basic principle is the most efficient public services should be held by the authorities who have the most minimal geographic control. The local government may have sufficient authority and access to financial resources, but if not managed carefully, decentralization will not generate benefits to the area. The results showed that in the public service of maternal and child health has not been encouraging. Many factors ynag cause, among other things: 1) Southeast Sulawesi is a province of the second lowest in Indonesia in the process of births attended by health personnel, 2) The worsening of the availability of Post Childbirth Village (Polindes) where the number of villages to be served by each of the sub decreased. The commitment of local government to provide a large enough budget in the health sector should dimbangi with the provision of health care facilities and services. Because of Southeast Sulawesi province is
\end{abstract}


actually the highest revenue earned on the island of Sulawesi but rather poverty was ranked 11th nationally.

\section{Keywords: Paradox, Decentralization of Health, Public Services, Maternal and Child} Health

\section{Pendahuluan}

Kebijakan untuk menurunkan angka kematian ibu dan anak harus melalui jalan yang terjal. Terlebih kala itu dikaitkan dengan target Milenium Development Goals (MDGs) 2015 (Magdalena, 2013), yakni menurunkan angka kematian ibu (AKI) menjadi 102 per 100.000 kelahiran hidup, dan angka kematian bayi (AKB) menjadi 23 per 100.000 kelahiran hidup yang harus dicapai. Indonesia memiliki angka kematian ibu dan anak tertinggi dibandingkan dengan negara-negara anggota ASEAN (Worldbank, 2001). Hal ini terjadi karena sebagian besar proses persalinan masih terjadi di rumah akibat ketidakmampuan ekonomi maupun tak terjangkaunya pelayanan rumah sakit atau puskesmas. Berdasarkan data Kementrian Kesehatan RI, tahun 2007 tercatat bahwa angka ibu melahirkan sebesar 228 per 100 ribu kelahiran dan angka kematian bayi sebesar 34 per seribu kelahiran hidup ${ }^{1}$.

IPM Sulawesi Tenggara sudah berada sedikit diatas rata-rata Kawasan Timur Indonesia, namun masih jauh dibawah rata-rata nasional. Pencapaian IPM Sulawesi Tenggara tahun 2009 sebesar 69,5. Peringkat IPM Sulawesi Tenggara masih stagnan pada posisi ke-25, atau ke-9 terendah secara nasional. Rendahnya IPM Sulawesi Tenggara terutama disebabkan masih rendahnya indikator harapan hidup

\footnotetext{
1 (www.ciputra news.com, Angka Kematian Ibu Ternyata Masih Tinggi, 15 Februari 2013
}

(BPS, 2011) ${ }^{2}$.

Padahal pendapatan pemerintah daerah perkapita Sulawesi Tenggara relative cukup tinggi dibandingkan provinsi lainnya dan berada diatas rata-rata nasional. Pada tahun 2010, pendapatan daerah perkapita Sulawesi Tenggara sebesar Rp 2,9 juta. Relatif lebih tinggi dibandingkan rata-rata pendapatan pemerintah daerah per kapita secara nasional sebesar Rp. 2,7 juta. Jika dibandingkan dengan provinsi lain di Pulau Sulawesi, Sulawesi Tenggara memiliki pendapatan daerah perkapita tertinggi. Padahal porsi belanja riil provinsi sektor kesehatan meningkat signifikan dari 7 persen tahun 2007 menjadi 8 persen tahun 2010 dan naik 19,7 persen tahun 2011. Peningkatan belanja kesehatan ini dilakukan untuk merealisasikan berbagai program dibidang kesehatan.

PAD yang tinggi diatas rata rata nasional dan belanja kesehatan 19,7\% ternyata tidak berpengaruh secara signifikan terhadap pelayanan kesehatan ibu dan anak di Sulawesi Tenggara. Ini bisa terlihat dari data bahwa angka kematian bayi (AKB), angka kematian balita (AKABA), dan kasus kematian Ibu meningkat pada tahun 2010. Penyebab kematian ibu maternal tahun 2008-2010 tertinggi disebabkan oleh kematian persalinan, kemudian kematian nifas dan kematian pada saat hamil (World Bank, 2012).

\footnotetext{
${ }^{2}$ BPS, 2011. Sulawesi Tenggara Dalam Angka.
} 
Masih belum menggembirakannya kinerja pembangunan di bidang kesehatan ibu dan anak di Sulawesi Tenggara bisa dilihat dari perkembangan capaian kinerja kesehatan di Sulawesi Tenggara menunjukkan terjadinya paradoks antara peningkatan output sektor kesehatan (berupa fasilitas pelayanan kesehatan) di satu sisi dan belum terjadinya perbaikan outcomes kesehatan (angka kesakitan, angka kematian bayi, angka kematian balita, kasus kematian ibu) di sisi lain. (World Bank, 2012)..

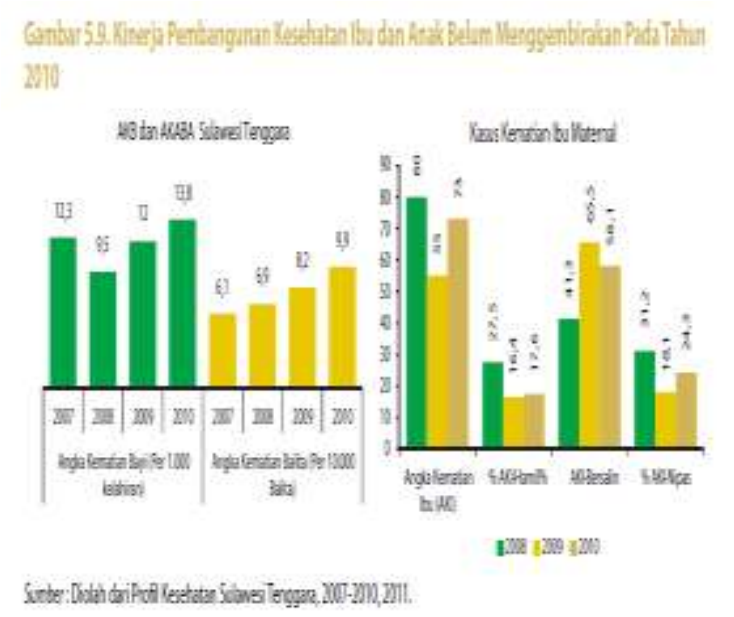

Secara nasional, cakupan kelahiran yang ditolong tenaga kesehatan di Indonesia sudah mencapai $80 \%$, Sulawesi Tenggara baru 53\%. Selain itu, meskipun cakupan imunisasi sudah cukup tinggi $(77 \%)$ dan mendekati angka nasional (78\%), namun dalam hal cakupan imunisasi lengkap (complete immunization), Sulawesi Tenggara masih yang terendah dibanding provinsi lain di Sulawesi. Dengan kondisi ini, tidak heran kalau tingkat kematian bayi dan kematian ibu di Sulawesi Tenggara masih terhitung tinggi (World Bank, 2012).

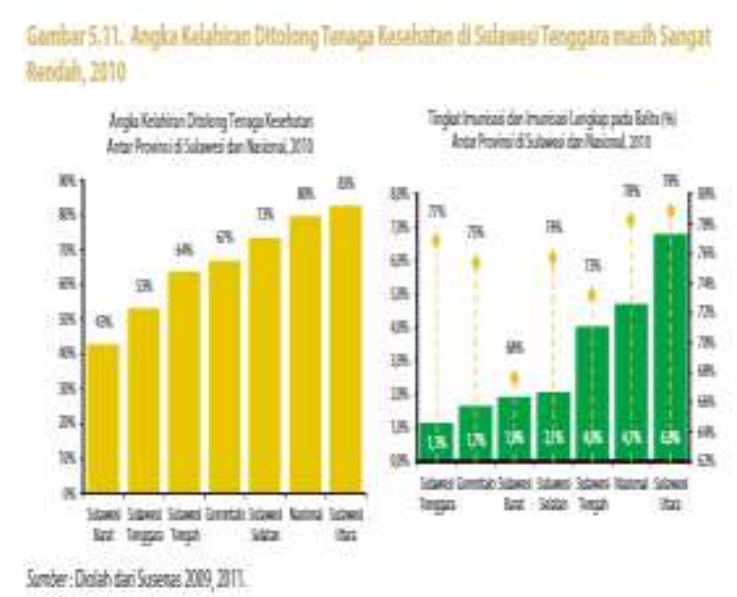

\section{Rumusan Masalah}

Berdasarkan uraian pada latar belakang, bahwa yang menjadi masalah dalam penelitian ini adalah: "Bagaimana pelayanan publik untuk kesehatan ibu dan anak di Provinsi Sulawesi Tenggara?"

\section{Metode}

Metode yang digunakan adalah studi kasus dengan menggunakan sumber data sekunder. Adapun metode yang digunakan yaitu penelusuran dan pemerolehan data yang diperlukan melalui studi pustaka.

\section{Pendekatan Teoritis}

\section{Desentralisasi Kesehatan}

Konsep desentralisasi dapat dilihat dari pandangan Smith yang mengatakan bahwa:

"Decentralization means both
reversing the concentration of
administration at a single
centre and conferring powers of local
government. Decentralization involves
the delegation of power to lower
levels in a territorial hierarchy,
whether the hierarchy is one of
government within a state or offices


$\begin{array}{lll}\text { within } & a & \text { large-scale } \\ \text { organization. } & \end{array}$

Pendapat di atas menjelaskan bahwa desentralisasi memiliki arti sebagai pemberian kekuasaan kepada Pemerintah Daerah melalui kewenangan administratif untuk mewujudkan pembangunan daerah. Desentralisasi dapat digunakan sebagai kewenangan daerah untuk mengatur dan mengurus kepentingan masyarakat setempat menurut prakarsa sendiri berdasarkan aspirasi masyarakat sesuai dengan kewenangan teritorial daerah yang bersangkutan. Oleh karenanya, dalam pelaksanaan desentralisasi diperlukan nilainilai daerah yang berkembang didalam masyarakat agar menghindari "over centralization".

Menurut Hoessein (dalam Muluk(2007:57) mengungkapkan bahwa local government ini mengacu pada dua prinsip. Pertama, the ultra vires doctrine menunjukkan pemerintah daerah dapat bertindak pada hal-hal tertentu atau memberikan pelayanan tertentu saja. Fungsi atau urusan pemerintahan yang tersisa menjadi kompetensi pemerintah pusat. Kedua, general competence atau open end arrangement merupakan kebalikan dari prinsip sebelumnya tersebut. Pemerintah daerah harus melakukan apa saja yang dipandang perlu dalam memenuhi kebutuhan daerahnya sebagaimana yang ditentukan oleh para pengambil keputusan di daerah itu. Pemerintah mempunyai urusan atau fungsi yang terinci, sementara sisanya merupakan fungsi atau urusan yang menjadi tanggung jawab pemerintah daerah.

Namun demikian, keberhasilan penyelenggaraan urusan pemerintahan di daerah sangatlah tergantung pada program

3 BC Smith. Decentralization, The Territorial Dimesion of the State. (London : George Allen \& Unwin Ltd, 1985). p. 1 kebijakan yang dibuat oleh Pemerintah Daerah. Kebijakan yang dibuat harus benar-benar berbasiskan kepada kepentingan daerah. Dalam perspektif UU No. 32 Tahun 2004 tentang otonomi daerah dijelaskan bahwa pemerintah pusat telah melimpahkan urusan kepada daerah otonom secara luas dan bertanggung jawab. Agar penyelenggaraan urusan pemerintahan tersebut dapat berjalan dengan efektif, maka diperlukan pola kerjasama antara Pemerintah Daerah, swasta dan masyarakat.

Pada dasarnya desentralisasi kesehatan adalah untuk memberikan pelayanan publik dalam rangka 1) merealisasikan pendekatan baru untuk menjalankan fungsinya pelayanan publik yang lebih baik ke arah manajerial daripada sekedar administratif, 2) sebagai respon terhadap skala penanganan dan cakupan tugas pemerintah, 3) perubahan dalam teori dan masalah ekonomi, dan 4) perubahan peran sektor swasta dalam penyelenggaraan pelayanan publik (Hughes, 1998) ${ }^{4}$. Karena didalam sistem kesehatan masyarakat, terdapat hubungan (relationship) antara negara dan masyarakat, yang tercermin melalui penyelenggaraan pelayanan. Oleh karena itu, pemerintah dengan kewenangan (authorities) yang dimiliki dapat menjadi pengendali dari sumber-sumber untuk kesehatan melalui regulasi dan kebijakan yang dibuat (Gostin, 2000) ${ }^{5}$. Meningkatnya perhatian pada masalah keadilan dan kesetaraan dalam penyediaan pelayanan kesehatan dan terbatasnya pilihan masyarakat terhadap pelayanan kesehatan menjadikan reformasi sektor kesehatan menjadi agenda penting di berbagai negara $(\mathrm{WHO}, 2000)^{6}$.

\footnotetext{
${ }^{4}$ Hughes, Owen E. 1998. Public Management and Administration An Introduction Second Edition. Great Britain. Macmillan Press Ltd.

5 Gostin O, Lawrence. 2000. Public Health Law: Power, Duty, Restraint. New York: University of California

${ }^{6}$ World Health Organization. 2000.
} 


\section{Pelayanan Publik}

Pelayanan publik (public service) oleh Widodo (2001:269) diartikan sebagai pemberian layanan (melayani) keperluan publik atau masyarakat yang mempunyai kepentingan pada organisasi itu sesuai dengan aturan pokok dan tata cara yang telah ditetapkan. Dalam Undang-Undang No. 25 tahun 2009 tentang Pelayanan Publik, menyatakan bahwa pelayanan publik adalah kegiatan dan rangkaian kegiatan dalam rangka pemenuhan kebutuhan pelayanan sesuai dengan peraturan perundang-undangan bagi setiap warga negara dan penduduk atas barang, jasa dan/atau pelayanan administrasi yang disediakan oleh penyelenggara pelayanan publik.

Sedangkan menurut Hughes (1998) menyebutkan bahwa karakteristik public service antara lain (1) public service lebih berorientasi pada pasar, (2) administrasi lebih fleksibel dengan menjamin keadilan pada (equity), (3) meningkatnya politisasi (yang bertolak belakang dengan model tradisional karena menolak campur tangan politik). Karena itu menurut Denhardt (2003:54), pemerintah seharusnya tidak hanya merespon kepentingan customers yang mementingkan diri sendiri dan berjangka pendek (the selfish and sort-term interests of customers), tetapi harus melayani kepentingan warga negara (civil servant serve citizens, not customers).

Peran negara (pemerintah) dalam hal pelayanan publik sangatlah besar, karena konsekuensi dari (UUD 1945) dan diterimanya filsafat negara kesejahteraan (welfare state) Negara tidak hanya berperan sebagai pengatur, pengontrol dan menegakkan peradilan, melainkan juga memberikan pelayanan pada masyarakatnya. Sehingga fungsi utama dari pemerintahan adalah fungsi pengaturan (regulation) dan fungsi pelayanan (service), sehingga kehadiran dari pemerintah adaah untuk mengatur dan melindungi dari warga negaranya agar senatiasa dalam keadaan aman dan tertib sekaligus sehat (Sarundajang, 2002) ${ }^{7}$.

\section{Pembahasan}

\section{A. PADTertinggi di Pulau Sulawesi Tapi Tingkat kemiskinan Teringgi ke 11 secara Nasional}

Smith (1985:24) menjelaskan bahwa tujuan desentralisasi akan menguntungkan Pemerintaha daerah dalam menyelenggarakan regionalisasi fungsi pemerintahan, tetapi pada kenyataannya PAD yang tinggi tidak berkolerasi dengan kehidupan yang lebih baik. Angka kemiskinan Sulawesi Tenggara Menurun dari sebesar 21,2 persen tahun 2007 menjadi 17,1 persen tahun 2010. Upaya menurunkan angka kemiskinan di Provinsi Sulawesi Tenggara melalui berbagai program penanggulangan kemiskinan baik yang dilaksanakan secara nasional maupun yang dilaksanakan oleh program dan kebijakan daerah telah menunjukkan hasil yang cukup baik. Namun demikian angka 17,1 persen masih termasuk tinggi dibanding dengan tingkat kemiskinan nasional sebesar 13,3 persen. Jika dilihat perbandingan antar provinsi di Pulau Sulawesi, Sulawesi Tenggara masih berada pada posisi ketiga tertinggi dibawah Gorontalo dan Sulawesi Tengah.

\footnotetext{
7 Sarundajang, SH.2002.. Arus balik Kekuasaan Pusat Ke Daerah, Pustaka Sinar Harapan. Jakarta.
} 
Pemerintah daerah Provinsi Sulawesi Tenggara sudah cukup merespon kewenangan di sektor kesehatan ini. Hal ini dibuktikan dengan anggaran belanja di sektor kesehatan sudah hampir mencapai 20\% sesuai amanat UU No. 36 Tahun 2009 Pasal 171 Ayat 2. Hal ini tidak terlalu sulit karena pendapatan Asli Daerah Sulawesi di atas rata-rata nasional. (World Bank, 2012).

\section{B. Ketimpangan Gender Dalam Pencapaian Kualitas Hidup Manusia}

Tiga dari empat indikator penentu Indeks Pembangunan di propinsi dan kabupaten/kota di Sulawesi Tenggara menunjukkan capaian pembangunan yang diterima perempuan lebih rendah dibandingkan dengan laki-laki. Indikatorindikator itu adalah indikator Angka Melek Huruf, Rata-rata Lama Sekolah serta Upah Buruh.

Padahal berdasarkan data realisasi belanja tahun 2009, dari 12 kabupaten/kota, 8 daerah sudah mengalokasikan belanja pendidikan 20 persen atau lebih, sementara 4 kabupaten masih dibawah 20 persen. Berdasarkan data realisasi tahun 2009, Muna merupakan kabupaten dengan belanja pendidikan tertinggi baik secara nominal maupun proporsional terhadap total belanja. Sementara itu, kabupaten dengan belanja pendidikan terendah adalah Wakatobi, dan kabupaten dengan proporsi belanja pendidikan terendah adalah Konawe Utara (10 persen).

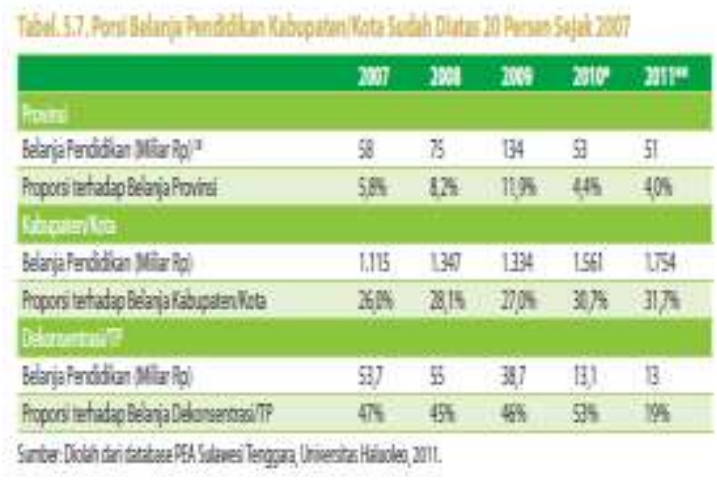

Meskipun sebagian besar kabupaten/kota sudah mengalokasikan 20 persen untuk pendidikan, belanja pendidikan per jumlah penduduk usia sekolah masih belum merata. Penduduk usia sekolah (7-15) merupakan salah satu penerima manfaat dari (benefeciaries) pembangunan pendidikan. Pemerintah kabupaten/kota memiliki kewajiban untuk memastikan penduduk usia tersebut memperoleh baik akses maupun kualitas pendidikan yang memadai. Namun demikian, dalam rangka memenuhi kewajiban tersebut, kesenjangan antar daerah masih sangat tinggi. Berdasarkan data tahun 2009, Konawe merupakan daerah dengan belanja pendidikan per penduduk usia sekolah terendah (Rp. 706 ribu per orang), sementara yang tertinggi adalah Kota BauBau dengan belanja pendidikan per penduduk hampir 6 kali lipat lebih besar dibanding Konawe (Rp. 3,7 juta). Tujuh dari 12 Kabupaten/kota mengalokasikan belanja pendidikan per penduduk usia sekolah dibawah rata-rata (BPS, 2011).

\section{Paradoks Pemerintahan Daerah Di Bidang Pelayanan Kesehatan Ibu dan Anak di Sulawesi Tenggara}

Sulawesi Tenggara merupakan provinsi yang memperoleh Pendapatan Asli Daerah 
tertinggi di Pulau Sulawesi dan mengalokasikan anggaran dibidang kesehatan sebesar 19,7\% ( amanat UU No. 36 Tahun sebesar 20\%). Belanja kesehatan 19,7\% (hampir mencapai 20\% sesuai amanat UU No 36 Tahun 2009 Pasal 171 Ayat 2) ternyata tidak berpengaruh secara signifikan terhadap pelayanan kesehatan ibu dan anak di Sulawesi Tenggara. Ini bisa terlihat dari data bahwa angka kematian bayi (AKB), angka kematian balita (AKABA), dan kasus kematian Ibu meningkat pada tahun 2010.

Angka kematian bayi di Sulawesi Tenggara pernah mengalami penurunan signifikan pada tahun 2008, namun kembali meningkat secara konsisten sampai 14 bayi per 1,000 kelahiran hidup. Tidak berbeda dengan AKB, AKABA juga mengalami peningkatan secara konsisten dari tahun ke tahun hingga hampir 10 balita per 10.000 balita. Jumlah kasus kematian ibu maternal pernah menurun pada tahun 2009, namun kembali meningkat pada tahun 2010. Penyebab kematian ibu maternal tahun 2008-2010 tertinggi disebabkan oleh kematian persalinan, kemudian kematian nifas dan kematian pada saat hamil (World Bank, 2012).

Di Provinsi Sulawesi Tenggara pelayanan kesehatan untuk ibu anak sudah cukup baik, ini bisa dilihat dari belanja langsung sektor kesehatan hampir mencapai 20\%, tetapi di 10 kabupaten dan 2 kota hanya mencapai 6-7\%. Ketimpangan inilah yang menyebabkan tidak meratanya pelayanan kesehatan di berbagai daerah.

Ketimpangan belanja kesehatan ini menyebabkan tidak meratanya pemerataan dan ketersediaan akses kesehatan bagi kesehatan ibu dan anak. Ini bisa dilihat dari data tentang keterjangkauan fasilitas kesehatan di Sulawesi Tenggara terus mengalami peningkatan kecuali (Pos Persalinan Desa) Polindes. Jumlah fasilitas kesehatan di Sulawesi Tenggara terus meningkat yang ditunjukkan oleh peningkatan rasio rumah sakit dari 1 rumah sakit per 100 ribu penduduk (2006) menjadi 1,6 (2010); rasio tempat tidur dari 4,3 per 10.000 penduduk (2006) menjadi 7,8 (2010); rasio Puskesmas dari 8,4 per 100 ribu penduduk (2006) menjadi 10,8 (2010); dan rasio Puskesmas pembantu (Pustu) dari 27,1 per 100 ribu penduduk (2006) menjadi 29 (2010). Selain itu, keterjangkauan pelayanan kesehatan juga terlihat semakin baik. Rasio Puskesmas meningkat dari 4,4 per $1000 \mathrm{~km} 2$ (2006) menjadi 6,3 (2010); dan jumlah desa yang harus dilayani oleh setiap satu Pustu menurun dari 4,1 desa (2006) menjadi hanya 3,4 desa (2010).

Perbaikan berbagai rasio ini menunjukkan pertumbuhan jumlah fasilitas kesehatan lebih tinggi dibanding peningkatan jumlah penduduk atau jumlah desa yang harus dilayani. Meskipun demikian, sampai tahun 2009, ketersediaan Polindes justru memburuk dari semula satu Polindes melayani 4 desa (2006) menjadi 11 desa (2009). (World Bank, 2012) ${ }^{8}$. Padahal Polindes menjadi pilihan pertama bagi ibuibu yang mau melahirkan di tingkat pedesaan. Sebagaimana diketahui Provinsi Sulawesi Tenggara terdiri-dari 10 kabupaten dan 2 kota. Artinya lebih banyak ibu-ibu dipedesaan dan juga balita yang akan membutuhkan pelayanan kesehatan di daerah pedesaan. Kalau

${ }^{8}$ Ibid 
pelayanan ini tidak mencukupi maka bisa dipastikan banyak ibu-ibu yang mau melahirkan tidak bisa mendapatkan pilihan pelayanan yang memadai. Sehingga ini akan berakibat pada semakin tingginya resiko keselamatan bagi ibu-ibu yang mau melahirkan, termasuk juga keselamatan bagi bayi yang akan dilahirkan.

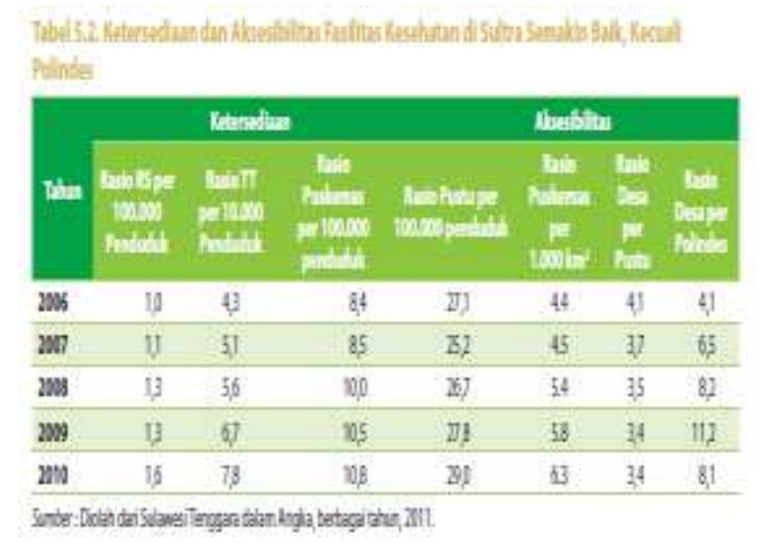

Paparan diatas sejalan apa yang disampaikan Bossert ${ }^{9}$, bahwa kendati pun desentralisasi diharapkan akan mendorong peningkatan cakupan, kualitas, pemerataan dan efisiensi pelayanan publik, dalam prakteknya penentuan prioritas kebijakan tidaklah berjalan linier. Hal ini sangat tergantung pada kemampuan penyelenggaraan pemerintah daerah dalam merespon perubahan tersebut, karena terjadi perluasan pilihan kebijakan pada tingkat lokal. Mekanisme dimana programprogram akan dibangun dan dilaksanakan untuk mengimbangi proses desentralisasi sangat tergantung komitmen pemerintah dalam menerjemahkan problem-problem daerah. Dalam kenyataannya, kewenangan mengatur dan mengurus yang dimiliki oleh pemerintah daerah tidak

9 Bossert, Thomas.1998. "Analyzing the Decentralization of Health System in Developing Countries: decision space, innovation, and performance", Social Science and Medicines. Vol.47, No. 10. London:Pergamon Press. berada pada ruang kosong (vacumm). Pemerintah daerah mungkin memiliki cukup otoritas dan akses pada sumbersumber leuangan, akan tetapi jika tidak dikelola dengan seksama, desentralisasi tidak akan menghasilkan manfaat bagi daerah.

Puskesmas atau Polindes sebagai suatu organisasi yang khusus memberikan pelayanan kesehatan pada masyarakat harus dilihat sebagai suatu institusi yang sangat fital demi kelangsungan hidup manusia. Penanganan pelayanan kesehatan di Puskesmas khususnya obstetri sering menjadi sorotan publik sebagai pengguna jasa pelayanan kesehatan yang sering merasa terabaikan dan tidak jarang berakhir pada kematian. Kematian dan kesakitan ibu sebenarnya dapat dikurangi atau dicegah dengan berbagai usaha perbaikan dalam bidang pelayanan kesehatan obstetri. Kegagalan dalam penanganan kasus kedaruratan obstetri umumnya disebabkan oleh kegagalan mengenal resiko kehamilan, keterlambatan rujukan, kurangnya sarana yang memadai untuk perawatan ibu hamil dengan risiko tinggi. Pendapat lain dari penyebab utama tingginya angka kematian ibu ialah adanya 3 terlambat (3T) yaitu terlambat mencari pertolongan, terlambat mencapai tempat tujuan dan terlambat memperoleh penanganan yang tepat setelah tiba ditempat tujuan. ${ }^{10}$

Padahal Oates yang dikenal dengan the decentralization theorm ${ }^{11}$ sudah

10 Laksono Trisnantoro: Jurnal Manajemen Pelayanan Kesehatan, Vol. 14, No. 2 Juni 2011

11 Shah, Anwar \& Shana Shah.2006. Local Governance in Developing Countries. Public Sector Governance And Accountability Series. The World Bank. p. 4 
menegaskan bahwa setiap pelayanan publik sebaiknya disediakan oleh yurisdiksi yang memiliki kontrol atas area geografis minimal, yang akan menginternalisasi manfaat dan biaya penyediaan.

"each public service should be provided by the jurisdiction having control over the minimum geographic area that would internalize benefits and costs of such provision," because; local governments understand the concerns of local residents; local decison making is responsive to the people for whom the services are intended thus encouraging fiscal responbility and efficiency, especially if financing of services is also decentralized; unnecesssary layers of jurisdiction are eliminated; interjurisdictional competition and innovation are enchanced".

Penyebab terlambatnya mencari pertolongan karena terlambat mencapai tempat tujuan dan terlambat memperoleh penanganan yang tepat setelah tiba ditempat tujuan. Hal ini terjadi apabila akses ke tempat persalinan jauh atau tidak ada sama sekali, sekalipun ada fasilitas untuk melakukan persalinan sangat minim. Ketersediaan Polindes yang semakin terbatas ini diperparah dengan Sulawesi Tenggara merupakan salah satu provinsi dengan angka terendah dalam hal cakupan kelahiran yang ditolong tenaga kesehatan serta imunisasi lengkap. Kelahiran yang dibantu tenaga medis profesional di Sulawesi Tenggara merupakan kedua terendah di Indonesia setelah Sulawesi Barat.

Secara nasional, cakupan kelahiran yang ditolong tenaga kesehatan di Indonesia sudah mencapai $80 \%$, Sulawesi Tenggara baru $53 \%$. Selain itu, meskipun cakupan imunisasi sudah cukup tinggi $(77 \%)$ dan mendekati angka nasional (78\%), namun dalam hal cakupan imunisasi lengkap (complete immunization), Sulawesi Tenggara masih yang terendah dibanding provinsi lain di Sulawesi. Dengan kondisi ini, tidak heran kalau tingkat kematian bayi dan kematian ibu di Sulawesi Tenggara masih terhitung tinggi (World Bank, 2012).

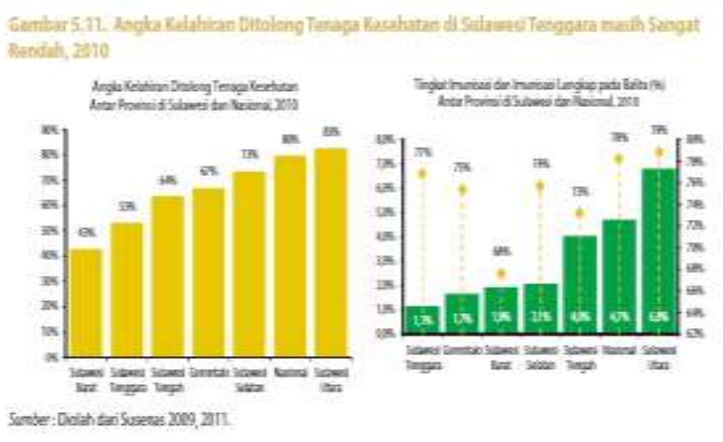

Di Provinsi Sulawesi Tenggara anggaran bidang kesehatan sudah cukup baik, ini bisa dilihat dari belanja langsung sektor kesehatan hampir mencapai $20 \%$, tetapi di 10 kabupaten dan 2 kota hanya mencapai 6-7\%. Ketimpangan inilah yang menyebabkan tidak meratanya pelayanan kesehatan di berbagai daerah.

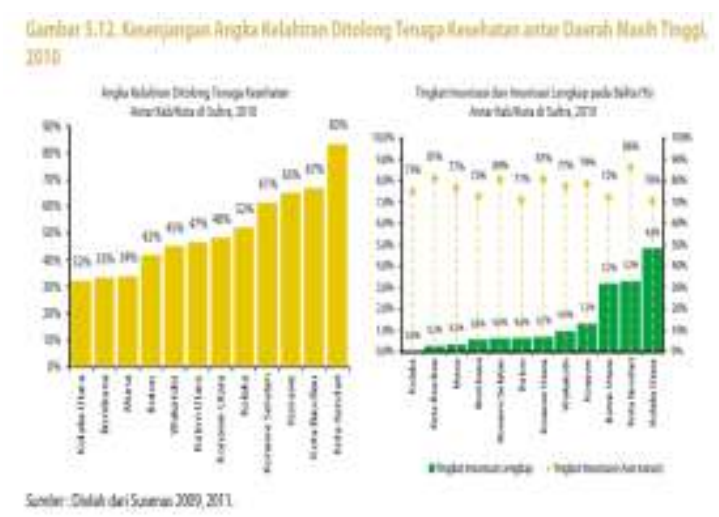

Masih terjadi kesenjangan ketersediaan dan aksesibilitas fasilitas kesehatan antar 
kabupaten/kota di Sulawesi Tenggara. Pada tahun 2010, rasio rumah sakit per 100 ribu penduduk tertinggi terdapat di Kota Kendari, namun di sisi lain dua kabupaten hasil pemekaran tahun 2007 (Buton Utara dan Konawe Utara) sama sekali belum memiliki rumah sakit. Meskipun beberapa daerah telah memiliki rumah sakit, namun tidak seluruhnya memiliki jumlah tempat tidur yang memadai. Di Kota kendari setiap 100 ribu penduduk tersedia lebih dari 16 tempat tidur, sementara di Bombana hanya 2 tempat tidur. Untuk rasio Puskesmas, Konawe Utara memiliki rasio tertinggi di Sulawesi Tenggara, namun dari sisi aksesibilitas masih sangat rendah. Jumlah Puskesmas per 1000 km2 di Konawe Utara hanya 2 unit sementara di Wakatobi bisa 44 unit lebih ( World Bank, 2011).

\section{Kesimpulan}

Penyelenggaran pemerintah daerah di Provinsi Sulawesi Tenggara dalam bidang kesehatan dengan capaian kinerja yang dilaporkan pada tahun 2011 menunjukkan terjadinya paradoks antara peningkatan output sektor kesehatan (berupa fasilitas pelayanan kesehatan) di satu sisi dan belum terjadinya perbaikan outcomes kesehatan (angka kesakitan, AKB, AKABA, kasus kematian ibu) di sisi lain. Hal ini terjadi karena dalam pemberian fasilitas pelayanan kesehatan belum memberikan pilihan kepada perempuan miskin untuk melahirkan. Pilihan kebanyakan perempuan miskin di pedesaan provinsi Sulawesi Tenggara adalah Polindes (Pos Persalinan Desa). Polindes adalah ujung tombak pertama yang bisa membantu ibu-ibu di pedesaan untuk melahirkan, karena bagi perempuan miskin tak ada pilihan lain karena Polindes biayanya murah dan terjangkau.

Pelayanan kesehatan ibu dan anak di Sulawesi Tenggara masih banyak yang perlu dibenahi, sehingga angka kematian ibu dan anak bisa ditekan seminimal mungkin. Hal ini perlu perhatian serius dari pihak pemerintah provinsi dengan memberikan penekanan perimbangan anggaran antara pemerintah provinsi dan kabupaten/kota. Perimbangan ini sangat penting, karena mayoritas perempuan yang membutuhkan pelayanan kesehatan berada di daerah pedesaan.

\section{Daftar Pustaka}

BPS, 2011. Sulawesi Tenggara Dalam Angka.

BC Smith. Decentralization, The Territorial Dimesion of the State. (London : George Allen \& Unwin Ltd, 1985). p. 44.

Bossert, Thomas.1998. "Analyzing the Decentralization of Health System in Developing Countries: decision space, innovation, and performance", Vol.47, No. 10. London:Pergamon Press.

Denhart, Janet V. And Robert B. Denhardt.2003. The New Public Service: Serving, not stering .USA:me.Sharpe Inc.

Gostin O, Lawrence. 2000. Public Health Law: Power, Duty, Restraint. New York: University of California Press

Hughes, Owen E. 1998. Public Management and Administration An 
Introduction Second Edition. Great Britain. Macmillan Press Ltd.

\section{Laksono Trisnantoro: Jurnal Manajemen} Pelayanan Kesehatan, Vol. 14, No. 2 Juni 2011

Magdalena dkk. 2013. Pelayanan Kesehatan untuk meningkatkan kesehatan ibu di Indonesia. Universitas Sumatera Utara.
Muluk, Khairul.M.R. 2007. Menggugat Partisipasi Publik Dalam Pemerintahan Daerah Bayu Media Publishing. Malang.

www. Kompas/Iwan Setiawan. 2013. Soal Kesehatan, Indonesia Tertinggal dari Tetangga.

www.ciputra news.com, Angka Kematian Ibu Ternyata Masih Tinggi, 15 Februari 2013 
Spirit Publik Volume 12, Nomor 1, April 2017 Halaman 57 - 68 